Revista da Faculdade Mineira de Direito |V.23 N.45|

\title{
UMA ABORDAGEM DA PROVA TESTEMUNHAL A PARTIR DA NEUROLAW
}

\author{
AN OVERVIEW OF THE TESTIMONLAL EVIDENCE BASED ON THE \\ NEUROLAW
}

\author{
Carlos André Maciel Pinheiro Pereira ${ }^{1}$ \\ UnP \\ Lia Rejane Muller Bevilaqua \\ UFRN
}

Bruno Tavares Padilha Bezerra ${ }^{3}$

Advogado

\begin{abstract}
Resumo:
Neste trabalho analisa-se a prova testemunhal no contexto do direito processual civil sob o enfoque da neurolaw. O estudo faz uma breve revisão sobre as características e natureza jurídica da referida prova, focando no testemunho de terceiros que aportam, sob compromisso de dizer a verdade, conhecimento subjetivo pertinente à lide. Utiliza o método indutivo, através de pesquisa qualitativa com suporte em fontes científicas, doutrinárias e legais com o intuito de melhor compreender metodologias que propõe a localização de circuitarias cerebrais relacionadas com o armazenamento de informações específicas e sua relação com a compreensão da prova testemunhal pelos atores do direito. As memórias não são perfeitas e a prova testemunhal é indissociável do processo de evocação da informação adquirida. Debate-se aqui as particularidades e características das memórias para que, quando transmitidas por um testemunho, possam ser devidamente escrutinizadas pelo julgador. Assim a eficácia da decisão judicial será maximizada ao alcançar a verdade material por trás do processo, ao mesmo tempo que salvaguarda a segurança jurídica.
\end{abstract}

Palavras-chave:

Prova testemunhal. Falibilidade das memórias. Neurolaw.

\begin{abstract}
:
This paper analyzes the testimonial evidence in the context of civil procedural law under the focus of neurolaw. Initially, the characteristics and legal nature of this type of evidence are briefly reviewed, focusing on the testimony of third parties who report, under the commitment to tell the truth, subjective knowledge relevant to a specific legal dispute. The inductive method is used, based on qualitative research supported by scientific, doctrinal and legal sources in order to understand new methodologies that propose to locate brain circuitries involved with specific information storage and how they contribute to the better understanding of testimonial evidence by legal players. Memory representations are not perfect and testimonial evidence depends on the recalling of acquired information. Here the characteristics and particularities of memories are debated so that, when transmitted by a testimony, they can be thoroughly scrutinized. In this way the efficacy of the judicial decision will be maximized as judges try to reach the material truth on the process, safeguarding the judicial security.
\end{abstract}

Keywords:

\footnotetext{
${ }^{1}$ Doutorando em Filosofia e Teoria do Direito pela Universidade Federal de Pernambuco (UFPE). Mestre, com distinção acadêmica, em Direito Constitucional pela Universidade Federal do Rio Grande do Norte (UFRN). Especialista em Direito Tributário pelo Instituto Brasileiro de Estudos Tributários (IBET). Professor da Escola de Ciências Sociais Aplicadas, Educação, Artes e Humanidades da Universidade Potiguar (UnP).

2 Pós-Doutorado na University of Newcastle, Austrália. Doutorado em Ciências Biológicas (Bioquímica) pela Universidade Federal do Rio Grande do Sul. Graduação em Farmácia e Bioquímica (modalidade Análises Clínicas) pela Universidade Federal de Santa Maria. mestrado em Genética e Biologia Molecular pela Universidade Federal do Rio Grande do Sul. Bacharelado em Direito pela Universidade Potiguar. Professora Adjunta do Instituto de Cérebro da Universidade Federal do Rio Grande do Norte.

${ }^{3}$ Mestre em Direito revalidado pela UFRN através da Universidade do País Vasco na Espanha. Doutorado em Direito na Espanha concluído. Bacharel em Direito pela Universidade Potiguar. Especialista em Processo Civil, especialista em Direito e Processo do Trabalho, Foi professor da Universidade Potiguar. Advogado.
} 


\section{Revista da Faculdade Mineira de Direito | V.23 N.45|}

Testimony. Memory Failure. Neurolaw.

\section{INTRODUÇÃO}

Testemunhar significa contar algo que ocorreu com fins de aportar veracidade a um determinado fato. No âmbito do direito, a atividade testemunhal desenrola-se em um contexto legal específico, no qual o que é asseverado por um terceiro não interessado em um litígio, sob juramento, assume um peso probatório que muitas vezes pode ser fundamental para a definição de uma causa. Uma busca pela palavra "testemunha" e pelo termo "prova testemunhal", nos Códigos Civil (CC) e de Processo Civil (CPC), resultou em 41 (quarenta e uma) e 85 (oitenta e cinco) entradas, respectivamente, o que atesta a presença deste meio probatório no ordenamento jurídico pátrio.

Para que algo possa ser relatado, é necessária a existência de memórias, as quais são armazenadas nas circuitarias neuronais sob a forma de registros químicos e físicos decorrentes do aprendizado, permitindo que a informação seja posteriormente acessada. A biologia da formação, modificação e evocação das memórias é uma das áreas de interesse da neurociência. Nessa direção, diversos artigos científicos sugerem que as memórias são falhas e sofrem interferência da sugestão, o que poderia levar à invalidação da aceitação da prova testemunhal (LACY e STARK, 2013; HOWE e KNOT'T, 2015).

Por outro lado, nem sempre é possível identificar e localizar a parte à qual se atribui um determinado ato ou obter provas objetivas que permitam a solução de um litígio e, nestes casos, um dos recursos que resta ao julgador para aproximar-se da verdade é a oitiva de testemunhas. Como, então, conciliar as dúvidas existentes sobre a confiabilidade das memórias e a prova testemunhal? É possível encontrar um meio termo no qual as imperfeições naturais dos processos cognitivos sejam levadas em conta no momento da valoração da prova testemunhal? Ou esta espécie probatória é, de fato, inútil e deve ser completamente eliminada do ordenamento jurídico?

A resposta para essas perguntas não é simples e exige a integração de conhecimentos de várias áreas. Ambos assuntos, memória e prova testemunhal, são inerentemente complexos. $\mathrm{O}$ direito é interdisciplinar por excelência, absorvendo constantemente conceitos e descobertas provenientes dos mais diversos campos de estudo. A neurolaw, por sua vez, é uma área de investigação já consolidada que integra os conhecimentos oriundos da neurociência com temas pertinentes ao direito.

Utilizou-se o método indutivo com alicerce na pesquisa qualitativa de obras doutrinárias escritas por processualistas de renome nacional e internacional, legislação codificada, legislação 
esparsa e artigos científicos com temática relacionada às características da aquisição e evocação da informação em um contexto jurídico.

Objetiva-se, no presente estudo, analisar a prova testemunhal no contexto do CC e do CPC sob a ótica da neurociência, com foco no estudo das características das memórias. Pretendese também apresentar e discutir a problemática do uso de exames de imagem com o intuito de identificar informações específicas armazenadas na circuitaria cerebral de indivíduos quando partes em um litígio.

A divisão dos tópicos segue a seguinte ordem: inicialmente, discorre-se sobre o ato de testemunhar, sua validade e dependência que a prova testemunhal tem dos mecanismos de armazenamento e evocação das memórias; a seguir, faz-se uma análise da função da prova no processo e sua importância para a formação da convicção motivada do juiz bem como do papel que o magistrado tem sobre sua produção; na sequência, determina-se a natureza jurídica das provas, em especial da prova testemunhal; após, o foco é dado para o papel da prova testemunhal no direito civil, seguido da análise das características das memórias e seus reflexos no ordenamento jurídico e, finalmente, conclui-se com uma proposta para uma teoria da prova sob o enfoque da neurociência.

Sendo assim e a partir de revisão da literatura específica, neste trabalho a memória será inquirida quanto à sua capacidade de armazenamento, estabilidade e reprodutibilidade no momento em que mais se exige um relato fidedigno dos eventos que a ela deram origem: a decisão, pelo juiz, entre a verdade do autor ou a do réu.

\section{TEORIA GERAL DA PROVA E OS PODERES INSTRUTÓRIOS DO JUIZ}

A prova pode ser definida como a ação e o efeito de provar demonstrando, de algum modo, a certeza de um fato ou a verdade de uma afirmação. No âmbito do sistema jurídico processual, a prova pode ter tanto um caráter de averiguação como de comprovação. A prova civil é considerada como método de comprovação, demonstração, corroboração da verdade ou falsidade das proposições formuladas em juízo, e não de averiguação ou investigação (COUTURE, 1958, p. 215-217).

As provas são fundamentais para estabelecer a verdade dos fatos e influir eficazmente na convicção do juiz. Tal princípio está protegido pelo artigo 369 do CPC, que preconiza: “as partes têm o direito de empregar todos os meios legais bem como os moralmente legítimos, ainda que não especificados no referido código, para provar a verdade dos fatos em que se funda o pedido 
ou a defesa e influir eficazmente na convicção do juiz.". Afinal, "a arte do processo não é essencialmente outra coisa que a arte de administrar as provas". (BENTHAN, 1971, p. 10)

A verdade almejada pela jurisdição, devido a motivos práticos e de celeridade processual, não é necessariamente a verdade real. Existe uma série de empecilhos que impossibilitam estabelecer exatamente como determinado fato ocorreu no passado, mas a busca pela verdade mais próxima da verdade real (verossimilhança) é o que se pretende e isto dependente da qualidade das provas disponíveis para o julgador.

Assim, a prova contribui para uma reconstrução fática, apresentando os elementos com a maior proximidade possível daquilo que ocorreu no tempo e no espaço (CAMBI, 2017, p. 563). A aludida reconstrução é um esforço complexo, pautado na contraposição dos interesses das partes com possível seletividade que induz uma persuasão mais benéfica a uma das partes (TARUFO, 2005, p. 50). O uso da informação depende dos interesses em questão e reflete o esforço que cada polo da lide faz para provar a sua verdade.

No afã de corroborar os fatos alegados, pode-se utilizar qualquer tipo de prova, previstas ou não na legislação processual, desde que lícitas e moralmente legítimas (art. 369, CPC). Se assim não fosse, o direito fundamental à tutela jurisdicional, previsto no artigo $5^{\circ}, \mathrm{XXXV}$ da Constituição Federal (CF), que diz que a lei não excluirá da apreciação do Poder Judiciário lesão ou ameaça ao direito, não estaria sendo observado.

O juiz tem um papel preponderante na condução do processo e entre suas funções está a de instruir adequadamente a lide, admitindo provas que sejam relevantes para o esclarecimento dos fatos em litígio e denegando aquelas que nada aportem para a sua solução. Moreira (1984, p.179) afirma que "se é função do juiz julgar, e julgar bem, e julgar com justiça, é sua função, por definição, aplicar as normas jurídicas a fatos”. Sendo assim e como previsto pelo artigo 370, CPC, caberá ao juiz, de ofício ou a requerimento da parte, determinar as provas necessárias ao julgamento do mérito.

Extrai-se do exposto que o julgador tem a liberdade para inquirir e investigar, no âmbito do processo civil, atividades classicamente associadas à produção da prova no direito penal. Referida atividade investigativa deverá ser uma exceção pois a prova civil não busca a averiguação da verdade real, mas procura pela verossimilhança a partir da verificação das provas trazidas ao processo pelas partes.

Em nenhum sistema jurídico o papel do juiz é absolutamente passivo. Por outro lado, o fato de que tenha poder sobre a produção e admissão das provas não o converte em agente parcial da justiça. A atuação do juiz é estabelecida e ao mesmo tempo delimitada pelo próprio 
ordenamento jurídico, o qual lhe impõe controles para que possa decidir racionalmente sem afrontar os valores fundamentais do processo civil. (TARUFFO, 2001, p. 35)

Como deve proceder o julgador para definir quais alegações devem ser provadas? Como evitar que incorra no risco de pré-julgamento ao descartar provas aparentemente relacionadas aos temas incontroversos? Em que situações deve o juiz determinar, de ofício, a produção de provas? Para realizar esta difícil tarefa, eivada de subjetividades, o juiz lançará mão das análises mais objetivas possíveis para decidir quais provas serão permitidas.

O juiz avaliará, entre outros aspectos, a pertinência e a admissibilidade da prova. Prova pertinente é aquela que versa sobre o objeto da prova, ou seja, sobre as proposições e fatos que se discutem em juízo. Já a admissibilidade refere-se à idoneidade de um determinado meio probatório para corroborar um fato. Por exemplo, seria inadmissível o arrolamento de testemunhas para corroborar um laudo pericial. (COUTURE, 1958, p. 238)

O tema da produção da prova não se resolve decidindo de antemão a quem corresponde a atividade probatória ou determinando um peso específico para distintos tipos de provas. $\mathrm{O}$ processo é dinâmico e depende da correta análise do litígio em tela. Justamente devido a isso é que a figura do juiz é central para a fase de instrução probatória. A partir da sua experiência e percepção da lide, é que poderá decidir se aceita ou não as provas propostas pelo autor e demandado bem como se existe a necessidade de produção adicional de prova ex officio, seja para investigar fatos importantes não trazidos à baila pelas partes ou para preencher lacunas que possam prejudicar o correto e célere andamento do processo.

O juiz não pode decidir levando em conta apenas opiniões pessoais. Para escolher a verdade que lhe parece legítima, o juiz precisa estimar, ponderar e avaliar os elementos subjetivos e objetivos relacionados ao caso concreto para, só então, alicerçado em critérios os mais objetivos possíveis, emitir decisão fundamentada. O sistema da persuasão racional, ou do livre convencimento motivado do juiz, adotado pelo ordenamento pátrio e previsto no artigo 93, IX, da CF, orienta a seleção dos critérios que devem ser observados quando da atividade de avaliação e valoração das provas.

Neste contexto, o juiz é livre para decidir, mas dentro de certos limites, devendo ficar condicionado aos fatos nos quais se funda a relação jurídica controvertida, às provas desses fatos trazidas ao processo, às regras legais e às máximas da experiência (SANTOS, 1982, p.14). Em outras palavras, o julgador deverá formar sua convicção seguindo regras de lógica jurídica, evitando entregar-se a impressões e convicções pessoais. Assim sendo, ao poder que é dado ao juiz para dirigir o processo da maneira que achar adequada, deve somar-se o controle subjetivo 
necessário para que a decisão proferida seja livre de elementos subjetivos que aportem parcialidade a ela.

\section{NATUREZA JURÍDICA DA PROVA TESTEMUNHAL}

A natureza jurídica da prova refere-se aos elementos fundamentais que integram sua composição específica contrapondo-os, para fins de classificação, ao conjunto mais próximo de figuras jurídicas. A especificação da prova testemunhal depende de suas características, ligadas às individualidades das pessoas que testemunham, e das particularidades das provas em geral. Neste sentido, Greco Filho (1996, p.212) aponta que os elementos que caracterizam a pessoa como testemunha são:

(a)é uma pessoa natural; (b) é uma pessoa estranha ao feito; (c) é uma pessoa que deve saber do fato litigioso; (d) a pessoa deve ser convocada regularmente a depor em juízo e (e) a pessoa deve ser capaz de depor e não pode estar impedida ou ser suspeita.

A questão sobre a natureza jurídica das provas sempre esteve aberta ao debate, não havendo posição doutrinaria conclusiva a respeito do tema. Em nosso ordenamento jurídico, discute-se sobre o caráter material ou processual da prova, com reflexos no âmbito da aplicação das normas no tempo, matéria de direito intertemporal. À guisa de contextualização e pertinente ao presente estudo, veja-se o problema da admissão da prova exclusivamente testemunhal em contratos particulares, desde a seara do direito material: o artigo 141 do antigo Código Civil de 1916 (CC16) previa que contratos cujo valor não ultrapassassem CR\$ 10.000,00 (dez mil cruzeiros) admitiam prova exclusivamente testemunhal para corroborar sua existência.

Tal previsão legal foi substituída pelo artigo 401 do já revogado Código de Processo Civil de 1973 (CPC73), que permitia a exclusividade da prova testemunhal para provar contratos cujo valor não ultrapassasse o décuplo do maior salário mínimo vigente no país ao tempo em que foram celebrados. Desta forma, se a norma reguladora da prova tivesse cunho exclusivamente processual, um contrato com valor superior ao previsto pelo CC16, mas inferior ao estabelecido pelo CPC73, que houvesse sido celebrado na vigência do CC16 e fosse julgado na vigência do CPC73, poderia ser comprovado apenas através da prova testemunhal.

Por outro lado, se a norma tivesse natureza material, no contexto do exemplo dado, a parte contratante não poderia provar seu contrato lançando mão do uso exclusivo da testemunha como meio probatório. Apesar de que as acima mencionadas leis já não estejam em vigor e do artigo 401 do CPC73 não ter sido recepcionado pelo CC, a discussão supracitada ainda é válida no sentido de que o resultado prático, consequência direta de como a matéria probante é 
enquadrada no ordenamento jurídico brasileiro, é diametralmente oposto dependendo de sua regulamentação pelo direito processual ou pelo direito material.

Neste sentido, traz-se exemplo no qual a mesma linha de raciocínio poderia ser aplicada em uma eventual revogação futura do CPC no que tange ao caráter de título extrajudicial dos contratos: atualmente, de acordo com o artigo 784, III, é título executivo extrajudicial o documento particular assinado pelo devedor e por duas testemunhas. Se, no futuro, tal artigo sofrer alteração quanto à necessidade das testemunhas ou até mesmo quanto ao número de testemunhas necessárias para atestar a extrajudicialidade do título, incorreríamos no mesmo tipo de discussão, que remete diretamente à caracterização do direito probatório como pertencente ao direito material ou processual.

Ainda com intuito exemplificativo, tome-se o caso do artigo 1.540 do CC: estando um dos contraentes em iminente risco de vida e não obtendo-se a presença da autoridade a quem incumba presidir o ato, nem a de seu substituto, poderá o casamento ser celebrado na presença de seis testemunhas que com os nubentes não tenham parentesco em linha reta ou, na colateral, até segundo grau. A norma, neste caso, é regulada pelo direito material ou processual? Certamente que as testemunhas têm um papel fundamental na situação apresentada para, perante o juiz, comprovar o negócio jurídico do casamento realizado, colocando-as no âmbito no direito formal. Por outro lado, a própria existência do negócio jurídico em questão depende da presença de um número específico de testemunhas, sem as quais não existirá, sendo da essência do ato e aproximando este tipo de prova ao direito material.

De maneira geral, os argumentos utilizados para classificar a matéria probatória como de direito material referem-se aos temas da eficácia e valoração da prova, derivados da exigência da estabilidade das convenções e da necessidade de contar de antemão com uma prova préconstituída bem como da eficácia a priori de certos negócios jurídicos (COUTURE, 1958, p. 258).

Por outro lado, os argumentos que colocam o tema probante no contexto do direito processual dizem respeito ao fato de que a prova, além de ser uma atividade dos litigantes (e excepcionalmente do julgador), é também um instrumento de convicção do juiz. É ele quem deve decidir, de maneira fundamentada e baseado nas provas que tenha admitido, desobrigando-se de meios probatórios que não sejam adequados (por mais que estejam previstos na legislação) e considerando a admissão de meios probantes modernos que porventura existam (COUTURE, 1958, p. 258).

A declaração das testemunhas tem natureza de prova, já que provoca a convicção de alguém sobre a existência (ou não) de atos, fatos, objetos. É meio de prova lícita e típica pois está prevista em diversos artigos do CC bem como nos artigos 442 a 463 do CPC. Ademais, tem 
Revista da Faculdade Mineira de Direito | V.23 N.45|

caráter processual, uma vez que a convicção que tende a provocar é a de um órgão jurisdicional, pois a testemunha se utiliza de um juízo para prestar seu depoimento. Por outro lado, pode considerar-se que tem caráter substancial se forem levadas em conta as normas de valoração e admissibilidade das provas. Quanto à pessoalidade, é prova pessoal, já que a lembrança e a narrativa de fatos têm caráter subjetivo.

\section{PROVA TESTEMUNHAL NO DIREITO PROCESSUAL CIVIL BRASILEIRO}

O direito civil brasileiro ampara-se, por excelência, em provas escritas: contratos públicos, particulares e de adesão, acordos, títulos de crédito, registros, tutela, curatela, entre outros, exigem registro escrito para sua eficácia. Por outro lado, justamente por regulamentar a maneira como os indivíduos se portam em sociedade e dada à incalculável quantidade de situações controversas que podem surgir, o relato de terceiros desinteressados eventualmente assume importância na solução de litígios nos quais a prova documental inexiste ou é insuficiente. Por mais que a prova documental tenha grande valor probatório no nosso ordenamento jurídico, é justamente o descumprimento do que está estabelecido no documento ou acordo que encaminha a desavença até a justiça, na busca pelo direito líquido e certo.

Nesta senda, pode-se afirmar que o correto cumprimento ou não de um acordo registrado em papel é algo que, em última análise, independe do documento em si. Depende, sim, do comportamento das pessoas, o qual decorre das decisões que tomam. O fator humano jamais poderá ser excluído das relações jurídicas interpessoais, mesmo que elas estejam firmemente ancoradas em documentos escritos.

Um olhar detalhado sobre o CC permite identificar a previsão da prova testemunhal em vários artigos, com fins de validação dos atos privados dos cidadãos. Neste sentido, analisa Assis (2016, p. 833):

\footnotetext{
Em relação às escrituras públicas, o art. 215 do CC, a regra consiste na facultatividade da participação das testemunhas instrumentárias (inciso II), exceto no caso de o tabelião não conhecer, nem puder o figurante identificar-se por documento, a teor do parágrafo quinto. As testemunhas instrumentárias (duas ou, conforme o caso, três) são necessárias nas várias modalidades de testamento; por exemplo, no art. 1864, II (testamento público), art. 1868, I (auto de aprovação do testamento cerrado), art. 1876, \$1. (testamento particular) do CC, sendo digno de registro que o art. 1865 do CC alude às "testemunhas instrumentárias". O assento de casamento necessita de testemunhas (art. 1536, VI, do CC). O artigo 221 caput, do CC, declarando que o instrumento particular assinado prova obrigações convencionais de qualquer valor, dispensou as testemunhas instrumentárias, comparativamente ao art. 135 do CC de 1916, na mais expressiva mudança legislativa na exigência de testemunhas privadas na prova documental. [...] No que tange aos instrumentos particulares, a notória confissão de dívida prevista no art. 585, II, adquirirá eficácia executiva, cuidando-se de documento particular, assinada pelo devedor e por duas testemunhas.
} 
Ainda, segundo Assis (2016, p. 833), dá-se o nome de “testemunha instrumentária à pessoa que intervém no documento público ou privado dando fé que assistiram a formação ou a assinatura, integrando a forma ad solenitatem dos negócios jurídicos”. Elas acrescentam à veracidade ou autenticidade dos negócios jurídicos "declarando", com sua assinatura, o conhecimento e consequente anuência com o que a lei está exigindo para sua concretização.

Este tipo de prova pode ser interpretada como um depoimento por antecipado ou, porque não, uma espécie de produção antecipada do testemunho (por analogia à produção antecipada da prova), o que agrega força probatória à situação jurídica concreta. Assim como ocorre com a declaração feita em juízo, a decisão de assinar um documento corroborando o que nele está escrito deve-se a uma análise do que foi percebido, através dos sentidos, pela testemunha. Mas, devido à imprevisibilidade inerente à própria vida, nem sempre é possível registrar o consentimento das partes em um documento escrito, e a reconstrução dos fatos deve ser feita a partir de relatos que podem ser tanto das partes como de terceiros indiferentes ao litígio, ou ambos.

No evento de desrespeito do que foi acordado por uma das partes, deve-se arbitrar uma solução que faça cessar o conflito. É no processo que as partes encontram um espaço seguro e imparcial para dirimir suas controvérsias ante a autoridade judicial e submetem-se, tácita ou expressamente, à decisão desta (COUTURE, 1958). Para tanto, as provas devem ser constituídas durante o processo mediante a atividade das partes e são denominadas circunstanciais (PALACIO, 2003).

$\mathrm{O}$ art. 378 do CPC preconiza que ninguém se exime do dever de colaborar com o poder judiciário para o descobrimento da verdade. Adicionalmente, o legislador processual definiu no art. 380, inciso I, que incube ao terceiro, em relação a qualquer causa, informar ao juiz os fatos e as circunstâncias de que tenha conhecimento. O dever de depor funda-se na solidariedade social e é considerado um serviço público, conforme previsão do art. 463, caput, CPC.

A admissibilidade da prova testemunhal está regulada nos artigos 442 a 448 do CPC e o art. 442 determina que a prova testemunhal sempre é aceitável, salvo quando a lei dispuser em contrário. Por outro lado, o art. 447, caput, estabelece que todas as pessoas podem ser testemunhas, exceto as incapazes, impedidas ou suspeitas, devidamente especificadas nos parágrafos $1^{\circ}, 2^{\circ}$ e $3^{\circ}$ do referido artigo.

No que tange à prova dos contratos, a legislação civil atual é bem clara ao dar força de prova plena ao instrumento particular feito e assinado ou somente assinado por quem esteja na livre disposição e administração de seus bens, independentemente do valor do bem (art. 221, CC), mas, mesmo assim, prevê o uso da prova testemunhal como subsidiária ou complementar 
da prova por escrito (art. 227, parágrafo único, CC). A norma do art. 221, CC, diz respeito à prova da existência física do contrato e não refere-se aos casos nos quais se discutem questões de fato a ele vinculadas.

As questões de fato e de direito são discutidas no âmbito processual. Sendo assim, havendo designação legal de prova escrita da obrigação, será admitida prova testemunhal quando houver começo de prova escrita emanada da parte contra a qual se pretende produzir a prova (art. 444, CPC). É também admissível a prova exclusivamente testemunhal naquelas situações nas quais tenha sido impossível registrar por escrito a obrigação, devido à relação de dependência entre os envolvidos bem como nos casos de depósito necessário (art. 445, CPC). Adicionalmente, o vício de consentimento e, nos contratos simulados, a divergência entre a vontade real e a vontade declarada pelas partes podem ser provados a partir do testemunho obtido em juízo (art. 446, I e II, CPC).

Por outro lado e em adição às já mencionadas limitações do art. 447, o CPC impede o uso da prova testemunhal quando o fato de prestar testemunho possa acarretar grave dano ao depoente ou a seus familiares (art. 448, I), quando exista sigilo profissional (art. 448, II), nos casos já provados por documento ou confissão da parte e perícia (art. 443, I), ou naqueles que só por documento ou exame pericial possam ser provados (art. 443, II).

Ademais, o CPC traz, nos artigos 450 a 463, o delineamento de como deve ser feita a produção da prova testemunhal, regulando a qualificação, arrolamento, substituição, momento e local do depoimento, ordem de inquirição e ressarcimento dos gastos que a testemunha teve para poder comparecer em juízo. Deles extrai-se também que a testemunha judicial precisa prestar compromisso de dizer a verdade (art. 458, caput, CPC), sob pena de incorrer no tipo do art. 342, caput, do Código Penal (CP), que prevê pena de prisão de 2 a 4 anos e multa para quem fizer afirmação falsa, negar ou calar a verdade, como testemunha, perito, contador, tradutor ou intérprete em processo judicial, ou administrativo, inquérito policial ou em juízo arbitral.

Os impedidos, os suspeitos e os menores de idade podem declarar em juízo em situações estritamente necessárias e de acordo com a discricionariedade do julgador, caso em que serão considerados informantes, pois não prestam compromisso de dizer a verdade, o que de maneira alguma os libera para mentir. O dever de dizer a verdade atinge a todos que participam do processo.

As testemunhas não vão a juízo para aportar dados técnicos ou especializados sobre a questão em debate. Sua função no processo é a de permitir que pessoas que de alguma maneira conheceram um fato, através de seus sentidos, possam relatá-lo à autoridade judicial para que esta valore tal declaração e emita uma decisão sobre a controvérsia suscitada entre as partes. 
Justamente pelo fato de que o testemunho, para ser fiel aos eventos passados, depende das informações armazenadas e da necessidade de que sejam lembradas, é que a compreensão das memórias e suas características é fundamental para auxiliar os atores do direito na incansável busca pela justiça.

\section{MEMÓRIAS, CARACTERÍSTICAS E REFLEXOS NO MEIO JURÍDICO}

A neurolaw é um campo de estudos reconhecido, produto da interface entre os avanços neurocientíficos e temas de interesse legal que não encontram subsídios satisfatórios em outras áreas do saber.

Nas palavras de Petoft (2015), neurolaw é uma área interdisciplinar que liga o cérebro à lei e contribui para o entendimento do comportamento humano, com o intuito de regulá-lo por meio da incorporação das descobertas neurocientíficas nos estudos legais.

No artigo The Overlooked History of Neurolaw, publicado em 2017, Shen faz um apanhado das distintas fases presentes na longa conversa entre neurociência e lei e identifica quatro momentos históricos: o diálogo médico-legal do século XIX, a introdução de evidências eletroencefalográficas no sistema legal na década de 1950, a controversa psicocirurgia utilizada na prevenção da violência nas décadas de 1960 e 1970 e a introdução do testemunho neuropsicológico nos anos 80 e 90.

Nos últimos 30 anos, temas de interesse do direito, tais como responsabilidade, culpabilidade, intenção, vontade, estados de consciência, quantificação da dor, agressão, autocontrole, impulsividade, demência, desordens de personalidade, tomada de decisão, melhoramento da função cerebral, entre outros, foram escrutinizados sob a ótica da neurociência.

Segundo Kogel, Scharama e Smit (2014), a neurociência trará importantes contribuições, no âmbito civil, em casos que envolvam: a) demandas por lesões físicas decorrentes de negligência, imperícia ou imprudência, nas quais a determinação da extensão, seriedade e consequências do dano será importante para a quantificação da compensação; b) determinação do estado de consciência em pacientes comatosos e decisões médico legais decorrentes sobre a continuação ou não da vida; reconhecimento legal de disforias de gênero amparadas em dados neurocientíficos e consequente permissão para alteração do registro de nascimento; d) uso da ressonância magnética funcional (fMRI, do inglês Functional Magnetic Ressonance Imaging) para determinar o estado de amadurecimento cerebral em adolescentes e jovens adultos e sua relação com a avaliação de riscos e tomada de decisão por parte deles. 
Para o estudo em tela, a neurolaw será uma ferramenta na compreensão das memórias e suas correlações com a prova testemunhal.

A discussão acerca da estabilidade, falibilidade e confiabilidade das memórias é antiga e deve-se, ao menos em parte, ao fato de que as lembranças (ou ausência delas) pregam peças frequentemente. É comum passar por situações nas quais o nome de uma pessoa conhecida não é lembrado, personagens de uma história confundem-se ou o carro é "perdido" em algum estacionamento de shopping. Mas uma coisa é enganar-se quanto ao local onde estão guardadas as chaves e outra, bem diferente, é depor em juízo, com plena certeza, acerca de um fato que, talvez, não condiz com a realidade.

Particularmente, em situações nas quais as memórias são evidência, não devem ser consideradas reproduções fidedignas de acontecimentos pretéritos. As recordações não representam os eventos exatamente como aconteceram no passado. A parte da experiência que é codificada depende, entre outras coisas, do que já está armazenado na memória, necessidades e estado emocional do indivíduo e da atenção dedicada ao desenrolar dos fatos.

Após adquirida, a informação estabiliza-se na forma de um traço mnemônico perdurável, o que ocorre através de um processo de filtragem e fixação progressivo denominado consolidação (MCGAUGH, 1966). Porém, as memórias não são imutáveis e podem tornar-se lábeis no momento de sua utilização (MISANIN et al., 1968). Para persistirem, precisam ser reconsolidadas (NADER et al., 2000), o que as torna suscetíveis para incorporação ou perda de conteúdo (DEBIEC et al., 2002; KIDA et al., 2002), indicando que a mera lembrança de um fato passado é potencialmente capaz de alterar a representação psíquica que dele formamos.

Por outro lado, para que possam ser declaradas, após terem sido armazenadas, as memórias devem ser evocadas. Evocar é lembrar. Para que isto aconteça, a circuitaria na qual a informação armazenada ficou física e quimicamente registrada precisa ser ativada e traduzir-se nas representações mentais que denominamos "pensamento", veículo abstrato através do qual explicitamos nossas memórias. Tende-se a considerar que a lembrança de eventos armazenados ocorre de maneira simples e automática: bastaria pensar no que se deseja lembrar que a memória apareceria de maneira fidedigna aos eventos originais.

As memórias não são perfeitas. Ao contrário do que se acredita, o processo evocativo é um processo ativo, no qual as memórias vão sendo "reconstruídas" na medida em que vão sendo pensadas e refletem uma integração de aspectos visuais, auditórios e táteis que complementam-se entre si e conferem a impressão de veracidade absoluta às nossas memórias.

Schacter (2001) propõe que as disfunções da memória podem ser resumidas no que ele denomina de "os sete pecados fundamentais": transiência, distração, bloqueio, atribuições 
equivocadas, sugestão, tendenciosidade e persistência. Os três primeiros pecados devem-se a algum tipo de omissão. A transiência refere-se ao enfraquecimento ou perda da informação ao longo do tempo; a distração deve-se a uma ruptura na interface entre a atenção e a memória; o bloqueio acontece quando a busca pela informação é frustrada. Os quatro pecados restantes são processos ativos nos quais algum tipo de memória está presente, mas é incorreta ou indesejada. As atribuições incorretas ocorrem quando há confusão em relação à origem de determinada informação; a implantação de memórias em decorrência de questionamentos, comentários ou perguntas direcionadas refere-se ao fenômeno da sugestão; memórias contaminadas por vivências e sentimentos pré-concebidos são tendenciosas; por último, a persistência mantém ativas memórias nas quais não conseguimos parar de pensar, por exemplo, em casos de estresse póstraumático.

O enfraquecimento das memórias, percebido como uma lembrança menos detalhada dos eventos na medida em que o tempo passa, pode dever-se a não consolidação da informação ou à perda do traço ao longo do tempo (transiência) ou, ainda, a ambos. Já a distorção, que ocorre quando aos eventos lembrados são adicionadas nuances e detalhes que não fazem parte da informação original, pode decorrer da sugestão, tendenciosidade e atribuições incorretas ou, ainda, de uma combinação entre todos. Somando-se a isto, devem-se considerar outros aspectos que influenciam na formação, evocação e declaração das memórias, tais como idade, grau de consciência e capacidade cognitiva dos indivíduos.

As distorções da memória são particularmente perigosas no âmbito legal. A prova testemunhal é um meio probatório por representação através de relatos derivados de processos reconstrutivos da memória humana. A menor eficácia das representações mediante relatos já era prevista por Couture (1958): as visões sofrem imperfeições derivadas do tempo transcorrido entre o fato e o relato, a memória apresenta falhas naturais resultantes da interferência de elementos alheios que não podem ser controlados e também a escrita, que registra fisicamente o relato, passa pelo crivo do escrivão, o qual, por mais que se proponha, não conseguirá ser perfeitamente fiel à versão da declaração por ele percebida.

Agregando complexidade ao tema, as testemunhas depõe sobre fatos que conheceram direta ou indiretamente e, sendo assim, as fontes do conhecimento a ser declarado podem ser classificadas como de ciência própria (direta; de visu; ocular) ou de ciência alheia (indireta; ex auditu). A testemunha direta é aquela que estava presente e vivenciou os eventos no momento em que aconteciam, ao contrário da indireta, que obrigatoriamente soube dos fatos por meio de relatos de outras pessoas, sejam elas as próprias partes, testemunhas diretas ou indiretas. O certo é que à medida em que aumenta o número de transmissões, mais frágil, imprecisa e insegura 
torna-se a informação, servindo muito pouco à formação do convencimento do juiz (ASSIS, 2016, p. 831).

Carvalho (1924, p. 78-79) já ressaltava a existência de uma fonte adicional do conhecimento, a qual denominou "fonte da crença própria", a qual trata da maneira como as imperfeições da memória imiscuem-se no que percebe-se como lembranças fidedignas de um evento passado. Por serem áreas relacionadas e indissociáveis, mas com terminologias tão distintas, a neurociência e o direito já vêm tratando do mesmo assunto, a falibilidade das memórias, o que fica visível apenas após uma análise detalhada dos temas pertinentes a ambas as áreas de estudo.

A prova testemunhal é considerada a prostituta das provas devido, por um lado, às distorções associadas com as memórias e, por outro, ao fato de que a declaração oferecida pode ser uma mentira intencional. Deve-se, então, eliminar este meio de prova com a consequente inviabilização dos depoimentos em juízo? E o que dizer daquelas situações que não deixam registro material e dependem exclusivamente dos relatos para serem verificadas? Em outras palavras, se as memórias são frágeis, como é possível lembrar de realizar tarefas habituais como comer, prestar um exame, ir a uma reunião no colégio dos filhos ou encontrar o caminho de casa?

O ser humano depende das memórias para levar adiante a vida e para que possa perceberse como seres individuais, graças ao repertório de experiências únicas vividas. Neste sentido e segundo Cammarota et al. (2008, p. 252), o acervo de nossas memórias faz com que cada um seja o que é, um indivíduo, um ser para o qual não existe outro idêntico. Se, por um lado, as memórias são potencialmente falíveis, por outro precisam ser confiáveis.

A questão é se a interface entre direito e neurociência será capaz de agregar conhecimento e tecnologias que, em última análise, poderão determinar a veracidade das memórias de interesse em um determinado litígio. O termo "falsas memórias" ficou amplamente conhecido após uma série de artigos publicados pela psicóloga americana Elizabeth Loftus e colegas, demonstrando a implantação de conteúdo inexato nas memórias de sujeitos experimentais (LOFTUS e PALMER, 1974; LOFTUS, 1975; LOFTUS e PICKRELL, 1995). Como consequência, tal expressão vem sendo corriqueiramente utilizada na psicologia para demonstrar que as memórias contêm informações imprecisas, inclusive sobre eventos nunca vivenciados pelo indivíduo.

O uso do termo "falsas memórias" é, desde a perspectiva bioquímica, inadequado e confuso. Se a memória para um determinado estímulo está codificada e armazenada em uma circuitaria específica, ou seja, existe fisicamente no cérebro, será muito difícil ou até impossível determinar bioquimicamente se é falsa ou verdadeira. No momento em que a informação ficou 
registrada no cérebro, mesmo que não seja condizente com a verdade real dos fatos, os mecanismos bioquímicos responsáveis por manter o traço mnemônico em uma forma perdurável possivelmente sejam os mesmos que aqueles utilizados para codificar memórias verdadeiras.

Em outras palavras, as falsas memórias, mesmo sendo falsas, são memórias. Sendo assim, as distorções que se incorporaram no registro físico-químico representativo de memórias de interesse em um determinado litígio terão de ser escrutinizadas por meio da corroboração dos fatos via oitiva de um número maior de testemunhas, quando possível. Desta maneira, distintas nuances percebidas em relação ao mesmo fato poderão ser comparadas e levadas em conta para a formação do convencimento do juiz.

Por outro lado e já parte do imaginário popular, a possibilidade de decifrar a circuitaria neuronal e encontrar informações específicas no emaranhado do tecido nervoso há muito habita as divagações humanas. A cada novo filme, onde cientistas com conhecimento das técnicas mais avançadas conseguem decifrar enigmas, verdades e falsidades por meio do uso de exames de imagem, surge a pergunta: será que a identificação de memórias específicas armazenadas no sistema nervoso é, de fato, possível? A resposta, do ponto de vista da validação experimental, ainda é indefinida.

Algumas empresas já oferecem serviços de análise da atividade cerebral com o intuito de identificar memórias específicas ou determinar se o indivíduo está mentindo ou dizendo a verdade. Destarte, a empresa norte americana Brain Fingerprint Laboratories ${ }^{4}$ assevera que é possível localizar memórias através do uso do eletroencefalograma (EEG), técnica que mede ondas cerebrais superficiais, entre elas a P300, potencial positivo evocado em resposta ao reconhecimento de estímulos alvo e cuja origem intracerebral e papel na cognição ainda não são completamente entendidos (PICTON, 1992). Lawrence Farwell (1991) reivindica para si a descoberta do método que ele denomina de brain fingerprinting (em português: assinatura cerebral).

Esta tecnologia, segundo seu criador, determina objetivamente qual informação está armazenada no cérebro de uma pessoa a partir de medidas das ondas cerebrais que ocorrem em resposta às palavras ou figuras relevantes apresentadas em uma tela de computador. A empresa utiliza a ondaP300 MERMER ${ }^{5}$ como um marcador cerebral do reconhecimento de lugares, objetos ou outros detalhes familiares ao indivíduo que está sendo testado. A P300, detectada na linha parietal medial, corresponde a um potencial evocado que combina o pico de voltagem positiva da onda P300 com um pico de voltagem negativa mais tardio e ocorre em torno de 300 milisegundos após o início do estímulo (FARWELL, 2013). O surgimento da P300 MERMER,

\footnotetext{
${ }^{4}$ Cf. http://www.larryfarwell.com

5 MERMER significa "memory and encoding related multifaceted electroencephalographic response" que em tradução livre corresponde a "resposta eletroencefalográfica à ativação de memórias".
} 
segundo o proprietário da empresa, está correlacionado com a ativação de memórias específicas para os estímulos apresentados (FARWELL, 2012).

De acordo com informações fornecidas no site da empresa, a tecnologia brain fingerprinting já foi utilizada em vários casos judiciais, entre eles o pedido de anulação da condenação de Steven Avery ${ }^{6}$ (protagonista da série da NetflixMaking a Murderer), a comprovação da inocência de Terry Harrington ${ }^{7}$, condenado erroneamente pelo assassinato do policial aposentado John Schweer, e a corroboração da culpabilidade de J. B. Grinder (FARWELL, 2012), assassino em série que confessou a morte de Julie Helton e de três outras pessoas após conhecer o resultado do brain fingerprinting nele realizado.

Com o intuito de estudar memórias adquiridas de maneira não intencional, Meixner e Rosenfeld (2014) adaptaram câmaras de vídeo para que 26 estudantes pudessem usá-las ao longo de 4 hs consecutivas enquanto realizavam atividades corriqueiras. O teste deu-se um dia após o final das gravações, através da apresentação de situações familiares ou não em uma tela de computador, enquanto as atividades cerebrais dos participantes eram registradas pelo EEG.

Os autores demonstraram a associação entre o reconhecimento de eventos vivenciados pelos sujeitos e o surgimento de um amplo pico na região do componente P300. Ressaltam que o estudo tem implicâncias para a aplicação do teste da informação escondida (CIT, do inglês Concealed Information Test), no qual aos suspeitos são apresentados vários estímulos, um dos quais está relacionado a um determinado crime $\left(\right.$ probe $^{8}$; por exemplo, revólver usado em um assassinato).

Os estímulos restantes consistem de itens controle da mesma classe que o probe (irrelevantes; por exemplo, outros tipos de armas que não o revólver). Espera-se, neste tipo de paradigma, que o indivíduo sem conhecimento do crime não consiga discriminar entre irrelevantes e probe. Concluem que o CIT/P300 poderia ser altamente eficiente para detectar informações adquiridas incidentalmente, com potencial uso no sistema legal.

Outra situação de interesse da neurolaw, relacionada à veracidade das memórias declaradas em juízo, é aquela na qual o indivíduo está mentindo. O que se espera da testemunha é que diga a verdade, mas o declarante pode não saber se está faltando com a verdade pois, até para mentir, existem variantes: uma pessoa pode mentir deliberadamente, pode mentir sem saber que está mentindo ou ainda porque foi treinada para enganar.

${ }^{6}$ Cf. https://www.cbsnews.com/news/making-a-murderer-attorneys-file-petition-for-new-trial/

${ }^{7}$ Cf. http://larryfarwell.com/Ruled-Admissible-dr-larry-farwell-brain-fingerprinting-dr-lawrence-farwell.html

${ }^{8}$ Probe, neste contexto, designa o estímulo que contém a informação de interesse; aquela que, supostamente, só o sujeito conhece e que se pretende averiguar através do brain fingerprinting. 
Desde o ano 2006, a empresa norte americana No Lie MRI ${ }^{9}$ oferece serviços de fMRI e garante que pode determinar se uma pessoa está dizendo a verdade ou não. No sítio virtual da No Lie MRI, a empresa esclarece que a tecnologia por eles desenvolvida representa a primeira e única maneira de medir a verdade e detectar a mentira na história da humanidade.

Ressaltam que o método funciona através da análise da atividade do sistema nervoso central, ao contrário do que oferece o tradicional polígrafo, que mede alterações nas respostas fisiológicas individuais, decorrentes do estresse associado ao ato de mentir. Listados juntamente com formulários para clientes (advogados, corporações, instituições governamentais e pessoas físicas), no site online da empresa, é possível encontrar indicações de publicações científicas sobre o produto oferecido bem como orientações para investidores. Enfatizam que a precisão do software desenvolvido para a detecção da verdade é atualmente de $93 \%$ e que chegará a 99\% no momento em que o produto estiver completo.

Ao contrário do oferecido pelo Brain Fingerprinting Laboratory, neste caso a atividade cerebral é decifrada a partir da atividade metabólica do cérebro quando sob o efeito de um forte campo magnético e as imagens produzidas permitem diferenciar circuitarias associadas a dizer a verdade ou mentir. Ainda, a detecção da mentira deve-se, segundo os criadores do método, à ativação característica e distintiva de áreas cerebrais envolvidas com o esforço e elaboração que o fato de mentir requer. De acordo com Pardo (2006), o trabalho mental exigido para elaborar uma mentira é maior que o envolvido em simplesmente recordar e reportar os conteúdos da memória, mas mesmo recordações verdadeiras podem ativar áreas cerebrais envolvidas com seletividade e criatividade.

A aplicação de técnicas de imagiologia cerebral que possibilitem verificar a credibilidade de uma testemunha está apenas no início. As empresas referidas neste estudo são as primeiras a oferecer, comercialmente, a possibilidade de localizar correlatos neurais associados ao armazenamento de informações específicas ou condutas, através do EEG ou fMRI. Por outro lado, críticas e questões éticas abundam quanto à validade e reprodutibilidade dos resultados obtidos, revisadas recentemente em Petoft e Abbasi (2019). Uma crítica importante refere-se ao fato de que grande parte das pesquisas realizadas para estabelecer a correlação entre ativação cerebral em regiões específicas e certos estados subjetivos reportam os resultados como médias obtidas a partir de um grupo de indivíduos testados.

A extrapolação de dados assim colhidos para a análise em nível individual será problemática bem como o será estabelecer comparações entre distintas regiões ativas em um mesmo indivíduo, no contexto legal, onde a disciplina ou cooperação por parte do acusado não

${ }^{9} \mathrm{O}$ nome No Lie MRI presta referência ao nome da empresa que oferece o serviço de detecção de mentiras através do uso da ressonância magnética funcional. Cf. https:// www.noliemri.com 
Revista da Faculdade Mineira de Direito | V.23 N.45|

são a regra (GOODENOUGH e TUCKER, 2010). Outros aspectos a serem levados em consideração referem-se ao número reduzido de participantes e desenhos experimentais que não mimetizam a complexidade das situações encontradas na vida real.

A jurisprudência brasileira ainda engatinha ao tratar da inexatidão das memórias, eis que atualmente apenas em alguns poucos casos a questão foi enfrentada pelos julgadores, ficando restrito a ações penais ${ }^{10}$. Dito isto, é evidente a potencial aplicação de testes que permitam a investigação sem filtros da maquinaria cerebral e, dada a complexidade do assunto, é necessário que ocorra uma ampla discussão entre neurocientistas e operadores do sistema jurídico com o intuito de potencializar a interface comunicativa entre a neurociência e o direito, representada pela neurolaw.

\section{CONCLUSÃO}

A neurolaw propõe o melhor entendimento do cérebro humano e suas funções em situações de relevância para o direito. Considerando que a mente é produto da atividade cerebral e o direito é criação da mente humana, a quantidade de temas que podem ser tratados sob este enfoque é ilimitada. A prova testemunhal, apesar de ser considerada pouco confiável, é muito utilizada no processo brasileiro. É difícil imaginar audiências nas varas de família ou trabalhistas, por exemplo, nas quais não haja a oitiva de testemunhas.

A neurociência está desvendando a bioquímica do sistema nervoso e sua correlação com o comportamento. As bases do pensamento, intenção e volição, capacidades que surgem da ativação de redes neurais, serão possivelmente decifradas. Em decorrência disto, novas

\footnotetext{
1010 Em busca realizada através do Portal Jusbrasil, utilizando "falsas memórias" como palavras-chave, são os seguintes julgados, que servem de exemplo, de maneira generalista, de qual maneira as memórias são tratadas:

APELAÇÃO CRIME. ATENTADO VIOLENTO AO PUDOR. SENTENÇA ABSOLUTÓRIA. LAPSO TEMPORAL ENTRE OS FATOS E A DENÚNCIA. POSSIBILIDADE DE FALSAS MEMÓRIAS. ABSOLVIÇÃO. Em que pese exista demonstração de um quadro crônico de violência doméstica no caso dos autos, envolvendo a ofendida e os demais familiares, a questão atinente ao delito de atentado violento ao pudor não restou demonstrada com a certeza necessária para a proalação (sic) de uma condenação. Quadro de violência física e psicológica que podem ter gerado falsas memórias, especialmente diante do lapso temporal de 10 anos entre o fato e a denúncia. RECURSO DESPROVIDO. (Apelação Criminal, No 70082112541, Sétima Câmara Criminal, Tribunal de Justiça do RS, Relator: Viviane de Faria Miranda, Julgado em: 17-10-2019)

APELAÇÃO CRIMINAL. ESTUPRO DE VULNERÁVEL. SENTENÇA ABSOLUTÓRIA. POSSIBILIDADE DE FALSAS MEMÓRIAS. MANUTENÇÃO. As percepções extraídas durante o acompanhamento psicológico do menino indicavam que havia uma violência em curso, embora houvesse dúvidas quanto ao cunho sexual ou não dos abusos. Foram realizados diversos pareceres psicológicos, que alternam ao indicar o acusado como pessoa idônea e de boa convivência ou como pessoa agressiva e descontrolada. Da mesma forma, no que se refere ao pai da vítima, alguns laudos o apontam como controlador e ameaçador, enquanto outros o qualificam como um pai atencioso e preocupado. Do quadro exposto, entendo que não é possível extrair-se dos autos, com absoluta certeza, que os fatos descritos na exordial aconteceram como narrados na inicial. E, em sede de processo penal, o juízo condenatório é um juízo de certeza, não podendo estar pautada a condenação em presunções ou suposições. Sentença absolutória mantida. RECURSO IMPROVIDO. (Apelação Criminal, No 70081919169, Sétima Câmara Criminal, Tribunal de Justiça do RS, Relator: Viviane de Faria Miranda, Julgado em: 17-10-2019)
} 
Revista da Faculdade Mineira de Direito | V.23 N.45|

tecnologias são desenvolvidas com o intuito de extrair, diretamente da circuitaria neuronal, informações relevantes para a lide. A aplicabilidade das metodologias abordadas neste trabalho ainda é tímida e restrita a alguns Estados estrangeiros e vem gerando críticas e questionamentos.

Dominguez e Esteban (2015) recomendam cuidado com os avanços da neurolaw devido aos riscos de que se tornem uma "neuroforça" livre das pertinentes discussões éticas. Segundo os autores, a maioria das aplicações derivadas do neuroimageamento encontram-se em estágios experimentais. Ressaltam que existem limitações morais ao uso de neuroimagens ou detecção da variação de ondas cerebrais, pois podem fornecer informações sobre o indivíduo que seriam inacessíveis aos métodos tradicionais de inquisição. Por outro lado, o uso da neurotecnologia a posteriori não define o "estado neural" do sujeito no momento em que cometeu o ilícito.

Deve-se ainda considerar, inter alia, os direitos constitucionais, como o que assegura o inciso LXIII do art5” da CF, que diz: "o preso será informado de seus direitos, entre os quais o de permanecer calado, sendo-lhe assegurada a assistência da família e de advogado". A nossa legislação protege o indivíduo quando the possibilita calar-se, blindando-o da auto-incriminação.

O ser humano não se detém facilmente frente a críticas ou considerações éticas, menos ainda quando existe potencial para a obtenção de lucro econômico por trás de descobertas inovadoras que encontrem um nicho de aplicabilidade no sistema legal. Neste trabalho, ofereceuse um vislumbre do que a neurolaw aporta para o entendimento de metodologias que visam identificar verdades ou mentiras diretamente nas circuitarias cerebrais e sua relação com a prova testemunhal, com fins de que esta discussão possa ser ampliada e aplicada na prática jurídica.

O destino deste tipo probatório no ordenamento jurídico será influenciado pela melhor compreensão dos processos de aquisição, armazenamento e evocação das informações e consequente desenvolvimento de técnicas que permitam a investigação objetiva de estados subjetivos. Assim, o emprego da prova testemunhal poderá ser otimizado pela neurociência, permitindo ao julgador e às partes auferirem, no curso da construção da verdade no âmbito processual, aquilo que é efetivamente relevante.

\section{REFERÊNCIAS}

ASSIS, Araken de. Processo civil brasileiro, volume III: parte especial: procedimento comum: (da demanda à coisa julgada). 2. ed. São Paulo: Revista dos Tribunais, 2016

\section{ATTORNEYS IN "MAKING A MURDERER" CASE FILE PETITION FOR NEW}

TRIAL. Nova Iorque, 07 jun. 2017. Disponível em: $<$ https://www.cbsnews.com/news/making-a-murderer-attorneys-file-petition-for-new-trial/>. Acesso em: 10 mai 2018 
Revista da Faculdade Mineira de Direito | V.23 N.45|

BENTHAN, Jeremy. Tratado de las pruebas judiciales. Trad. de Manual Ossorio Florit. Buenos Aires: Jurídicas Europa-América, 1971

BRASIL. Código civil. Disponível em:

<http://www.planalto.gov.br/ccivil_03/leis/2002/110406.htm>. Acesso em: 05 mai. 2018

BRASIL. Código de processo civil. Disponível em:

<http://www.planalto.gov.br/ccivil_03/_ato2015-2018/2015/lei/113105.htm>. Acesso em: 05 mai. 2018

CAMBI, Eduardo. et. al. Curso de processo civil completo. São Paulo: Revista dos Tribunais, 2017

CAMMAROTA, Martin; BEVILAQUA, Lia Rejane; IZQUIERDO, Iván. Aprendizado e Memória. In: LENT, Roberto. (Org.). Neurociência da mente e do comportamento. Roberto Lent (coord.). Rio de Janeiro: Guanabara Koogan, 2008, p. 241 - 252

COUTURE, Eduardo J. Fundamentos del derecho procesal civil. 3 ed. Buenos Aires: Roque Depalma Editor, 1958

DEBIEC, Jacek; LEDOUX, Joseph E.; NADER, Karim. Cellular and systems reconsolidation in the hippocampus. Neuron, v. 36, n. 3, p. $527-538,24$ out 2002

DOMINGUEZ, Daniel P.; ESTEBAN, Elsa G. The ethical implications of considering neurolaw as a new power. Ethics \& Behavior, v. 26, n. 3, p. 1 - 15, fev 2015

FARWELL, Lawrence A.; DONCHIN, Emanuel. The truth will out: interrogative polygraphy ("lie detection") with event-related potentials. Psychophysiology, v. 28, n. 5, p. 531 - 547, set 1991

FARWELL, Lawrence A. Brain fingerprinting: a comprehensive tutorial review of detection of concealed information with event-related brain potentials. Cogn. Neurodyn v. 6, n. 2, p. 115 154, fev 2012

FARWELL, Lawrence A. Farwell brain fingerprinting ruled admissible as scientific evidence in court: innocent man freed after 24 years in prison. Disponível em: $<$ http:/ / larryfarwell.com/Ruled-Admissible-dr-larry-farwell-brain-fingerprinting-dr-lawrencefarwell.html>. Acesso em: 10 mai 2018

FARWELL, Lawrence A.; RICHARDSON, Drew C.; RICHARDSON, Graham M. Brain fingerprinting studies comparing P300-MERMER and P300 brainwave responses in the detection of concealed information. Cogn. Neurodyn, v. 7, n. 4, p. 263 - 299, dez 2013

GOODENOUGH, Oliver R.; TUCKER, Micaela. Law and cognitive neuroscience. Ann. Rev. Law. Soc. Sci, v. 6, p. $61-92$, dez 2010

GRECO FILHO, Vicente. Direito processual civil brasileiro. 12. ed. São Paulo: Saraiva, 1996

HOWE, Mark L; KNOTT, Lauren M. The fallibility of memory in judicial processes: lessons from the past and their modern consequences. Memory, v. 23, n. 5, p. 633 - 656, jan 2015 
KIDA, Satoshi et al. CREB required for the stability of new and reactivated fear memories. Nat Neurosci. Berlim, v. 5, n. 4, p. 348 - 355, abr 2012

KOGEL, Catharina H.; SCHRAMA, Wendy M.; SMIT, Monika. Civil law and neuroscience. Psychiatry, Psychology and Law, v. 21, n. 2, p. 272 - 285, mar 2014

LACY, Joyce W.; STARK, Craig E. L. The neuroscience of memory: implications for the courtroom. Nat. Rev. Neurosci, v. 14., n. 9, p. 649 - 658, set 2013

LOFTUS, Elizabeth F; PALMER, John C. Reconstruction of automobile destruction: An example o the interaction between language and memory. Journal of Verbal Learning \& Verbal Behavior, vol. 13, n. 5, p. 585 - 589, out 1974

LOFTUS, Elizabeth F. Leading questions and the eyewitness report. Cognitive Psychology, v. 7 , n. 4 , p. $560-572$, out 1975

LOFTUS, Elizabeth F.; PICKRELL, Jacqueline E. The formation of false memories.

Psychiatric Annals, v. 25, n. 12, p. 720 - 725, dez 1995

MCGAUGH, James L. Time dependent processes in memory storage. Science. Pensilvânia, v. 153, n. 3.742, p. $1351-1358$, set 1966

MEIXNER, John. B.; ROSENFELD, J. Peter. Detecting knowledge in incidentally acquired, real-world memories using a P300-based concealed-information test. Psychological Science, Victoria, v. 25, n. 11, p. $1-12,11$ set 2014

MISANIN, James R.; MILLER, Ralph R.; LEWIS, Donald J. Retrograde amnesia produced by electroconvulsive shock after reactivation of a consolidated memory trace. Science, v. 160, n. 3.827 , p. $554-555$, mai 1968

NADER, Karim; SCHAFE, Glenn E.; LEDOUX, Joseph E. Fear memories require protein synthesis in the amygdala for reconsolidation after retrieval. Nature, v. 406, n. 6.797, p. $722-$ 726 , ago 2000

NO LIE MRI. 2006. Disponível em:

<http://www.noliemri.com/pressNPubs/Publications.htm>. Acesso em: 06 maio 2018

PALACIO, Lino E. Manual de derecho procesal civil. 17 ed. Buenos Aires: Abeledo Perrot, 2003

PARDO, Michael S. Neuroscience, evidence, legal culture and criminal procedure. American Journal of Criminal Law, v. 3, n. 3, p. $301-337$, jun 2006

PETOFT, Arian. Neurolaw: a brief introduction. Iran J. Neurol., v. 14, n. 1, p. 53 - 58, jan 2015

PETOFT, Arian; ABBASI, Mahmoud. Current limits of neurolaw: a brief overview. Médecine \& Droit, Paris, dez 2019

PICTON, Terence. W. The P300 wave of the human event-related potential. J. Clin.

Neurophysio, Filadélfia, v. 9, n. 4, p. 456 - 479, out 1992 
SANTOS, Moacyr A. Comentários ao código de processo civil, Lei n. ${ }^{\circ}$ 5.869, de 11 de janeiro de 1973, vol IV: arts. 332 - 475. Rio de Janeiro. Forense, 1982

SCHACTER, Daniel L. The seven sins of memory: how the mind forgets and remembers. Cambridge: Houghton Mifflin Company. 2001

SHEN, Francis X. The overlooked history of neurolaw. Fordham Law Review, v. 85, n. 2, p. $667-695$, jan 2017

TARUFFO, Michele. Aspetti Fondamentali del Processo Civile di Civil Law e di Common Law. Revista da Faculdade de Direito UFPR, Curitiba, v. 36, n. 1, p. 27- 48, 2001. Disponível em: $<$ https://revistas.ufpr.br/direito/article/view/1780>. Acesso em: 06 maio 2018 